\title{
Los colores del tejido adiposo
}

María E. Frigolet ${ }^{1 *}$ y Ruth Gutiérrez-Aguilar ${ }^{1,2}$

${ }^{1}$ Hospital Infantil de México "Federico Gómez", Laboratorio de Enfermedades Metabólicas, Obesidad y Diabetes; ${ }^{2}$ Universidad Nacional Autónoma de México, Facultad de Medicina, División de Investigación. Ciudad de México, México

\section{Resumen}

El tejido adiposo es un órgano endocrino con gran actividad metabólica. A la fecha se han descubierto innumerables adipocinas y lipocinas, péptidos y lípidos con actividad biológica, secretadas por el tejido adiposo. Se sabe que tanto el tejido adiposo blanco como el pardo y el beige contribuyen a la homeostasis energética y a la regulación metabólica. Esta revisión tiene como finalidad comunicar los hallazgos más recientes relativos al tejido adiposo según su color y la relación de este con las alteraciones metabólicas asociadas a la obesidad. Después de la revisión de la literatura especializada, se identificó que en una misma estructura pueden coexistir poblaciones blancas, pardas y beige, que modifican el estado metabólico global en situaciones fisiológicas o patológicas.

\section{PALABRAS CLAVE: Tejido adiposo. Adipocito. Metabolismo.}

\section{The colors of adipose tissue}

\section{Abstract}

Adipose tissue is an endocrine organ with high metabolic activity. Countless adipose tissue-secreted adipokines and lipokines, as well as peptides and lipids with biological activity have thus far been discovered. Both white and brown and beige adipose tissue are known to contribute to energy homeostasis and metabolic regulation. The purpose of this review is to report on the most recent findings related to adipose tissue according to its color and its relationship with metabolic alterations associated with obesity. After a review of the specialized literature, white, brown and beige adipocyte populations were identified to be able to coexist within the same structure, and to modify global metabolic state in physiological or pathological situations.

KEY WORDS: Adipose tissue. Adipocyte. Metabolism.

\section{Generalidades del tejido adiposo}

El tejido adiposo representa entre 20 y $28 \%$ de la masa corporal de los individuos sanos, porcentaje que varía de acuerdo con el sexo y el estado energético, de tal forma que la masa grasa puede constituir hasta $80 \%$ de la masa corporal en los individuos con obesidad. La distribución y localización de dicha masa grasa determinan su función. El tejido adiposo subcutáneo, localizado debajo de la piel, representa la mayor proporción de tejido adiposo. ${ }^{1}$ El tejido adiposo visceral rodea los órganos, especialmente el riñón (tejido adiposo perirrenal), los intestinos (tejido adiposo mesentérico y omental), las gónadas (tejido adiposo epididimal y parametrial), la vasculatura (tejido adiposo perivascular o periadventicial) y el corazón (tejido adiposo epicárdico y pericárdico) ${ }^{2}$ (Figura 1).

El tejido adiposo pertenece al grupo de los tejidos conjuntivos que confieren cohesión a los órganos 0
Correspondencia:

*María E. Frigolet

E-mail: maruf.himfg@gmail.com
Fecha de recepción: 17-09-2019

Fecha de aceptación: 03-01-2020

DOI: 10.24875/GMM.20005541
Gac Med Mex. 2020;156:143-150

Disponible en PubMed

www.gacetamedicademexico.com

0016-3813/@ 2020 Academia Nacional de Medicina de México, A.C. Publicado por Permanyer. Este es un artículo open access bajo la licencia CC BY-NC-ND (http://creativecommons.org/licenses/by-nc-nd/4.0/). 


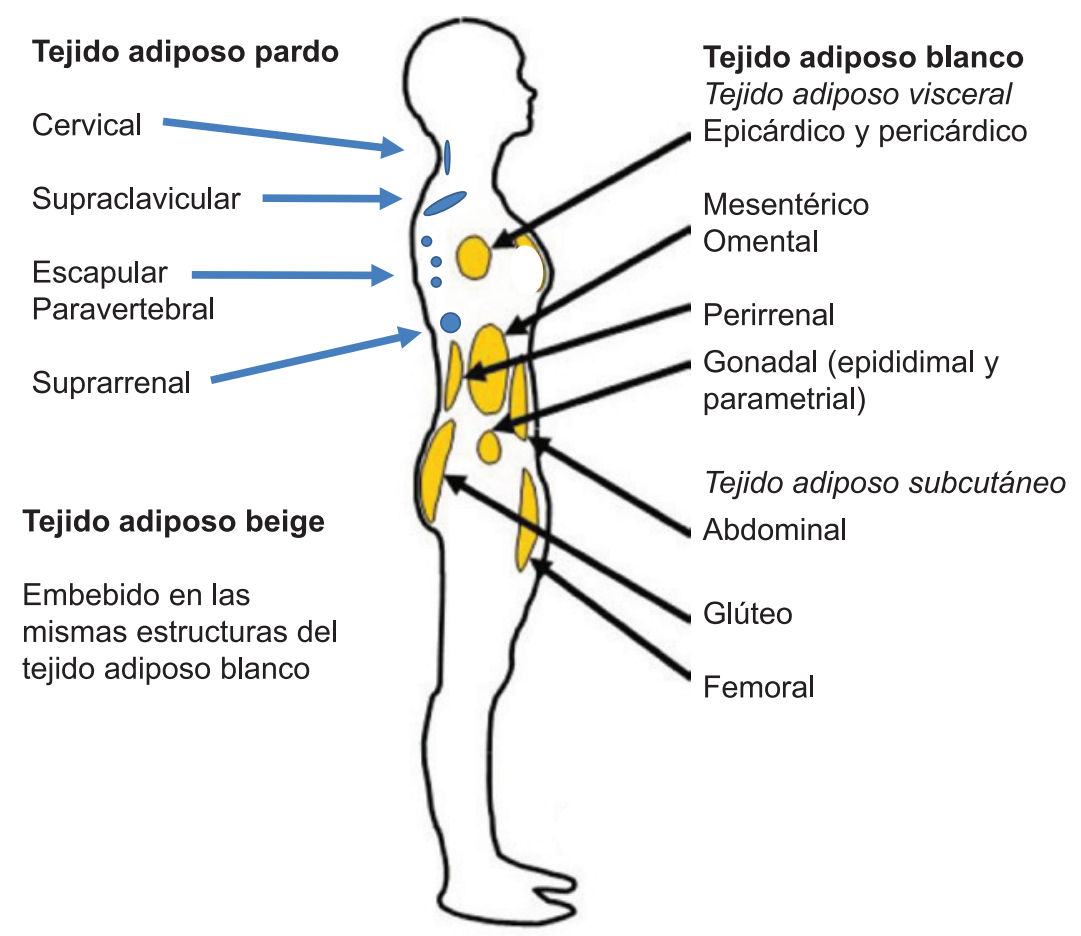

Figura 1. Localización de los tejidos adiposos blanco, pardo y beige. En amarillo, las estructuras de tejido adiposo blanco y en azul, los depósitos de tejido adiposo pardo.

sistemas. Un ejemplo claro de esta función es la del tejido adiposo mesentérico, el cual mantiene las circunvoluciones del intestino delgado en una posición más o menos constante. ${ }^{3}$ Además de la función de soporte de estructuras, el tejido adiposo regula de forma muy importante el balance de energía. Recientemente se determinó que el tejido adiposo no es solo un almacén de energía o un órgano pasivo del metabolismo, sino que influye y participa en el estado energético. De hecho, se le ha considerado un órgano endocrino capaz de secretar hormonas que viajan por el torrente sanguíneo para llegar a sus tejidos blanco. Otras funciones del tejido adiposo se refieren a la regulación de procesos fisiológicos como el dimorfismo sexual, la inmunidad, la reproducción, la adipogénesis, la angiogénesis, la reestructuración de la matriz extracelular, el metabolismo de esteroides, la hemostasia y el mantenimiento de la temperatura corporal. ${ }^{4,5}$

La ejecución de dichas funciones está dada por los diversos tipos celulares que conforman el tejido adiposo: adipocitos, preadipocitos, fibroblastos, macrófagos, monocitos, células del estroma vascular y células de innervación. La mayor proporción de células en este tejido parece no estar representada por los adipocitos, sino por las demás células. De hecho, hasta $80 \%$ del total del ADN extraído del tejido adiposo proviene de células vasculares, fibroblastos, leucocitos y macrófagos. ${ }^{6}$

Existen tres tipos de tejido adiposo según sus funciones, coloración, vascularización y estructura (Figura 2):

- Tejido adiposo blanco.

- Tejido adiposo pardo.

- Tejido adiposo beige.

\section{Tejido adiposo blanco}

El tejido adiposo blanco se caracteriza por ser un tejido blanco o amarillo con menor vascularización e inervación que el pardo. Las células adiposas del tejido adiposo blanco tienen un tamaño que va de 20 a $200 \mu \mathrm{m}$ y son uniloculares, es decir, contienen una sola vacuola lipídica. En dicha vacuola se almacenan lípidos para su utilización cuando existe demanda de energía. Del total de lípidos que engloba la vacuola lipídica del adipocito blanco, entre 90 y $99 \%$ son triacilgliceroles. ${ }^{3}$ Los triacilgliceroles depositados en la vacuola lipídica contienen suficiente energía para cubrir los requerimientos energéticos de un adulto sano durante al menos dos meses.

El tejido adiposo blanco genera gran cantidad de adipocinas y lipocinas. Las adipocinas son péptidos que actúan como hormonas o mensajeros que 


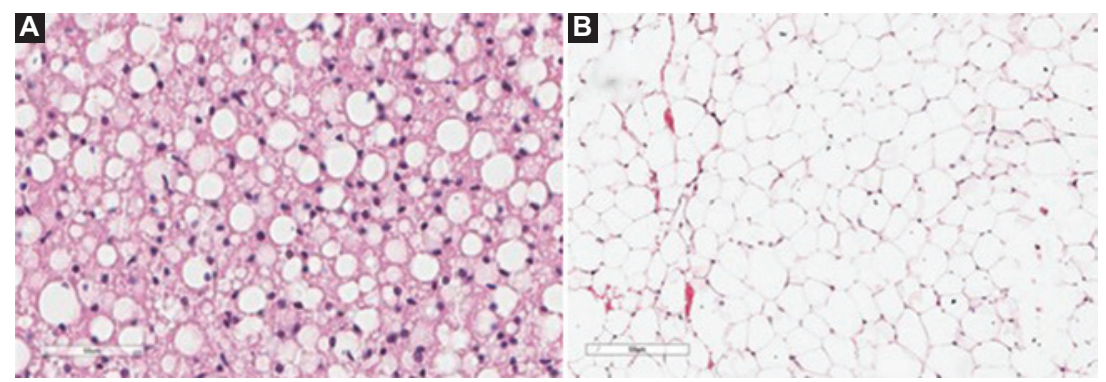

Figura 2. Histología del tejido adiposo pardo A: y del blanco B: tinción con hematoxilina y eosina, 40x, escala de 50 um. Nótese que los adipocitos pardos contienen varias vacuolas lipídicas, que el tejido está sumamente inervado y que los núcleos están localizados de forma indeterminada. El tejido adiposo blanco está menos inervado y contiene una gran vacuola lipídica por célula, razón por la cual el núcleo está localizado hacia la periferia y se observa aplanado.

regulan el metabolismo. Se estima que $40 \%$ de los genes que expresa el tejido adiposo son novedosos en su función y se calcula que 20 o $30 \%$ de estos representan proteínas de secreción. ${ }^{7}$ Conocemos que el tejido adiposo secreta proteínas con gran versatilidad de funciones relacionadas con las citocinas proinflamatorias, la inmunidad, el complemento, el sistema fibrinolítico, el sistema renina-angiotensina, el metabolismo y transporte de lípidos y las enzimas del metabolismo de los esteroides, entre otras. Por esas razones se considera que el tejido adiposo es un órgano endocrino que produce adipocinas como la adiponectina o la procineticina o la relacionada con meteorina ${ }^{8,9}$ Las lipocinas, de naturaleza lipídica, ejercen la misma función al ser secretadas por el adipocito e influir en el metabolismo.

Entre las décadas de 1950 y 1970, los estudios de parabiosis mostraban la existencia de factores circulantes que regulaban el peso corporal: se observó que al introducir sangre de roedores delgados en roedores obesos se normalizaba el peso de los últimos. ${ }^{10-12}$ En 1994, el doctor Friedman y su grupo describieron por primera vez uno de estos factores. Se trataba de la leptina, una proteína secretada primordialmente por los adipocitos y, por lo tanto, una adipocina. La leptina está conformada por 167 aminoácidos, pesa $16 \mathrm{kDa}$, pertenece a la familia de las citocinas y es considerada una hormona anorexigénica por causar saciedad. En los animales, la infusión local de leptina en el hipotálamo reduce el consumo de energía y el peso corporal. ${ }^{13}$ En principio se pensó que este sería el esperado antídoto contra la obesidad, pero los estudios clínicos demostraron que el efecto biológico de la hormona no era significativo. En una entrevista para The Journal of Clinical Investigation, el doctor Friedman aseguró que la mayoría de los pacientes produce suficiente leptina, sin embargo, su acción está disminuida en los individuos obesos, lo que se considera resistencia a la leptina. ${ }^{14}$

Ahora sabemos que la hiperleptinemia en la obesidad se asocia con resistencia a la leptina, hiperfagia y aumento en la capacidad de almacenamiento de lípidos y oxidación de estos en el tejido adiposo y órganos periféricos. ${ }^{15-18}$

Posteriormente se descubrió la adiponectina, una adipocina de $30 \mathrm{kDa}$ que forma hexámeros y dodecámeros, ${ }^{19}$ asociaciones de alto peso molecular que promueven la sensibilidad a la insulina, aumentan la oxidación de los lípidos en músculo e hígado y disminuyen la expresión de moléculas de adhesión y citocinas proinflamatorias. En los humanos, la hipoadiponectinemia se relaciona con obesidad, diabetes y síndrome metabólico. ${ }^{20}$

La omentina también es una adipocina con efectos favorables sobre el metabolismo; se encuentra en menor concentración en la circulación de individuos con obesidad, diabetes tipo 2 o enfermedad cardiovascular. La omentina ejerce sus funciones mediante la activación de vías de señalización de insulina e inhibición de vías inflamatorias y procesos aterogénicos. ${ }^{21}$

Otras adipocinas como la resistina, proteína de unión al retinol o RBP-4, quemerina y visfatina están aumentadas en el suero de individuos con obesidad y promueven la resistencia a la insulina y el riesgo cardiovascular, ${ }^{22}$ por lo cual contribuyen al síndrome metabólico.

Como se mencionó, existe un grupo de moléculas nombrado lipocinas. La lipogénesis de novo en el tejido adiposo da lugar a ácidos grasos como el palmitoleato (16:1n7) y los ácidos grasos-hidroxilo-ácidos grasos (AGHAG), a los que se les atribuyen efectos metabólicos favorables. ${ }^{23}$ Se ha mostrado que el palmitoleato regula la expresión de genes lipogénicos en el hígado, promueve la sensibilidad a la insulina en hígado y músculo $^{24}$ y antagoniza los efectos inflamatorios producidos 
Tabla 1. Descripción de algunas adipocinas/lipocinas, órgano secretor, influencia sobre el consumo de energía y el metabolismo

\begin{tabular}{|c|c|c|c|}
\hline Adipocina/lipocina & Órgano o tejido secretor & Orexigénico/anorexigénico & Efecto metabólico \\
\hline Leptina & $\begin{array}{l}\text { Adipocitos, epitelio del estómago } \\
\text { y del intestino, placenta, músculo, } \\
\text { glándula mamaria y cerebro }\end{array}$ & Anorexigénico & $\begin{array}{l}\text { Saciedad, oxidación de lípidos, } \\
\text { termogénesis, sensibilidad a la insulina }\end{array}$ \\
\hline Adiponectina & Adipocitos & Anorexigénico & $\begin{array}{l}\text { Oxidación de lípidos, supresión de } \\
\text { gluconeogénesis hepática, inhibición de } \\
\text { adhesión de monocitos (antiinflamatorio y } \\
\text { antiaterogénico) }\end{array}$ \\
\hline Omentina & $\begin{array}{l}\text { Células del estroma vascular del } \\
\text { tejido adiposo visceral y células } \\
\text { intestinales }\end{array}$ & Orexigénico & $\begin{array}{l}\text { Mayor captura de glucosa estimulada } \\
\text { por insulina y liberación de péptidos } \\
\text { orexigénicos en el hipotálamo }\end{array}$ \\
\hline Resistina & Adipocitos & Anorexigénico & $\begin{array}{l}\text { Resistencia a la acción de la insulina y } \\
\text { síntesis de ácidos grasos en hígado }\end{array}$ \\
\hline $\begin{array}{l}\text { Proteína de unión al } \\
\text { reintol-4 }\end{array}$ & Adipocitos & - & $\begin{array}{l}\text { Transporte de retinol y resistencia a la } \\
\text { acción de la insulina por menor expresión } \\
\text { de GLUT4 }\end{array}$ \\
\hline Quemerina & $\begin{array}{l}\text { Adipocitos, hepatocitos y células } \\
\text { de pulmón }\end{array}$ & $\begin{array}{l}\text { Orexigénico si es infundido } \\
\text { crónicamente }\end{array}$ & $\begin{array}{l}\text { Adipogénesis, angiogénesis, } \\
\text { proinflamatorio }\end{array}$ \\
\hline Visfatina & $\begin{array}{l}\text { Adipocitos en el tejido adiposo } \\
\text { visceral }\end{array}$ & - & $\begin{array}{l}\text { Posible influencia en el desarrollo } \\
\text { de obesidad, proinflamatorio y } \\
\text { proaterogénico }\end{array}$ \\
\hline Ácido palmitoleico & Adipocitos & - & $\begin{array}{l}\text { Sensibilidad a la insulina, menor } \\
\text { lipogénesis }\end{array}$ \\
\hline $\begin{array}{l}\text { APHAE (ácido palmítico- } \\
\text { hidroxil-ácido esteárico) }\end{array}$ & $\begin{array}{l}\text { Tejido adiposo subcutáneo y } \\
\text { perigonadal en ayuno }\end{array}$ & - & $\begin{array}{l}\text { Sensibilidad a la insulina por mayor } \\
\text { captura de glucosa, mayor secreción } \\
\text { de insulina y del péptido-1 similar a } \\
\text { glucagón, antiinflamatorio }\end{array}$ \\
\hline
\end{tabular}

por el ácido graso palmítico en modelos animales de obesidad inducida por la dieta. ${ }^{25-27}$ También como producto de la lipogénesis de novo en el tejido adiposo, el APHAE, un isómero de los AGHAG que consiste en un ácido palmítico (16:0) y un ácido esteárico (18:0), se encuentra regulado por ciclos de ayuno-posprandio y sus concentraciones elevadas se han asociado con mayor sensibilidad a la insulina. ${ }^{28}$ En estudios clínicos se mostró que los pacientes resistentes a la insulina cuentan con menor concentración de $\mathrm{APHAE}^{29}$ (Tabla 1).

La proporción de adipocinas o lipocinas liberadas con acción antiinflamatoria en relación con las de acción proinflamatoria y proaterogénica influye en el establecimiento de las alteraciones metabólicas que acompañan a la obesidad. Finalmente, el desequilibrio en la producción de adipocinas es reflejo de la pérdida de la funcionalidad de los adipocitos en condiciones de exceso energético. La capacidad de amortiguar la abundancia energética almacenando lípidos en el tejido adiposo se debe a la adecuada expansión de este tejido, característica de una adecuada funcionalidad de este tejido.
De hecho, el tejido adiposo blanco sano puede expandirse de forma dramática, más que ningún otro tejido, en respuesta a cambios en el estado energético y como resultado de un mayor depósito de lípidos y menor tasa de utilización de estos. El tejido adiposo puede crecer por hiperplasia y por hipertrofia. ${ }^{30} \mathrm{La}$ hiperplasia es el aumento en el número de adipocitos y la hipertrofia es el aumento del tamaño de los mismos. En estados fisiológicos de crecimiento como la adolescencia y la gestación, el tejido adiposo crece, principalmente por medio de hiperplasia. En la edad adulta, la capacidad de maduración de los preadipocitos declina. ${ }^{31}$ Se ha demostrado que la expresión del receptor 2 activado por proliferadores de peroxisomas gamma (PPAR- $\gamma$ ), uno de los reguladores clave de la adipogenésis, es mayor en individuos jóvenes que en adultos mayores. ${ }^{32}$ El tejido adiposo crece por hipertrofia como consecuencia de la incapacidad para madurar preadipocitos. Los adipocitos hipertróficos son los que pueden liberar mayor concentración de ácidos grasos libres y mayor proporción de adipocinas proinflamatorias. ${ }^{33}$ Esto se acompaña de modificaciones en el flujo sanguíneo 
del tejido y de mayor proceso fibrótico, lo cual causa muerte celular. ${ }^{34}$

Finalmente, la hipótesis del tejido adiposo disfuncional vincula el exceso de energía con el riesgo cardiometabólico. Por esta razón, la comunidad científica ha profundizado en el metabolismo del tejido adiposo con la finalidad de prevenir dichos riesgos.

\section{Tejido adiposo pardo}

La coloración parda del tejido adiposo se debe a que este se encuentra más vascularizado y con gran contenido de mitocondrias, las cuales, a su vez, poseen citocromos, responsables de dar color. Las células adiposas que conforman al tejido adiposo pardo son multiloculares o con varias vacuolas lipídicas. Estas células tienen una forma poligonal y miden de 15 a $50 \mu \mathrm{m} .{ }^{31}$ El tejido adiposo pardo tiene una célula progenitora (positiva para la expresión de Myf5) en común con el músculo esquelético, ${ }^{35}$ es decir, los adipocitos pardos no provienen de los blancos, sino de células precursoras de músculo.

Al contrario que el tejido adiposo blanco, el pardo no tiene la función de almacenar energía, sino que disipa la energía mediante termogénesis. Para lograr la regulación de la temperatura corporal, el tejido adiposo pardo se localiza en sitios superficiales y profundos. En sitios superficiales se encuentran las regiones interescapulares, cervicales y axilares, mientras que en los sitios profundos están los tejidos adiposos pardos perirrenales, periaórticos, inguinales y pericárdicos. ${ }^{30}$ En los humanos, las regiones interescapulares, axilares y cervicales adquieren especial importancia (Figura 1).

La presencia de tejido adiposo pardo es especialmente clara en la etapa neonatal. De hecho, por mucho tiempo se había pensado que el tejido adiposo pardo estaba muy restringido en masa después del nacimiento. Sin embargo, en varios estudios recientes se ha demostrado que el tejido adiposo pardo en humanos está representado por varias estructuras de tejido metabólicamente activo. ${ }^{36-38} \mathrm{La}$ exposición al frío y la sobrealimentación aumentan la actividad y tamaño de estas estructuras, mientras que la edad las disminuye. ${ }^{39}$ En cambio, en los roedores, el tejido adiposo pardo se mantiene durante toda la vida y contribuye de forma muy importante al gasto de energía por termogénesis. ${ }^{40}$

La activación de los receptores betaadrenérgicos en el tejido adiposo pardo promueve la estimulación de las proteínas desacoplantes (UCP), las cuales utilizan el flujo de protones de la fosforilación oxidativa produciendo calor en lugar de ATP. Hasta la fecha se han identificado y clonado tres isoformas de UCP: UCP1 y UCP2, que se expresan en el tejido adiposo blanco, mientras que UCP3 se expresa principalmente en el tejido adiposo pardo y músculo esquelético. ${ }^{41}$ Es en las mitocondrias del tejido adiposo pardo donde se produce calor por la función de las UCP y, como consecuencia, se incrementa el gasto de energía. Cuando el alimento no está disponible, las señales de hambre del hipotálamo activan las neuronas gabaminérgicas, las cuales bloquean la activación del sistema simpático para disminuir la termogénesis en el tejido adiposo pardo y reducir el gasto de energía. ${ }^{42}$

Hay evidencia de que el tejido adiposo pardo, al igual que el blanco, regula la homeostasis energética respondiendo al estado metabólico global. Al respecto, la descripción del proceso de transdiferenciación o interconversión ha dado pistas sobre la posibilidad de que el tejido adiposo blanco sea transformado en pardo. En modelos animales adultos se conoce que la masa grasa en regiones anatómicas como la epididimal y la interescapular está compuesta primordialmente por tejido adiposo blanco y pardo, respectivamente. Sin embargo, en el tejido adiposo epididimal se ha comprobado la presencia de adipocitos pardos y en el interescapular, la presencia de adipocitos blancos.

Existen condiciones, como la mayor concentración de hormonas tiroideas, ácidos biliares, péptidos natriuréticos y retinoides, que aumentan el número de adipocitos pardos en el tejido adiposo blanco..$^{43}$ El desarrollo de adipocitos pardos en depósitos blancos se ha asociado con menor riesgo de desarrollo de obesidad y diabetes ${ }^{44-47} y$ se consigue con la exposición al frío y con el tratamiento con agonistas de receptores betaadrenérgicos ${ }^{48} \mathrm{Al}$ contrario, la conversión de adipocitos pardos en blancos se ha demostrado en modelos animales de obesidad inducida por dieta. ${ }^{49}$

Probablemente con la profundización del entendimiento de la transdiferenciación, en el futuro se podrá disponer de herramientas que ofrezcan una estrategia preventiva o terapéutica para la obesidad.

\section{Tejido adiposo beige}

Recientemente se mostró que en respuesta a ciertos estímulos como el ejercicio, la exposición al frío o a algunas hormonas, podían aparecer células adiposas parecidas a los adipocitos pardos, con coloración beige y positivas a la expresión de UCP1. ${ }^{50}$ Estas 
se pueden acumular en los depósitos clásicos de tejido adiposo blanco y se les ha llamado adipocitos beige o "brite" (combinación de los términos brown y white).

Aun cuando los adipocitos beige tienen características similares a los pardos, como su morfología (contienen varias vacuolas lipídicas), tienen distintas localizaciones anatómicas. Mientras que los adipocitos beige están inmersos en las regiones subcutáneas del tejido adiposo blanco, los pardos se encuentran primordialmente en las regiones superficiales mencionadas (Figura 1).

Los adipocitos pardos y los beige parecen desarrollarse a partir de distintos precursores embrionarios. ${ }^{51}$ Como se comentó, los adipocitos pardos se originan de células positivas a Myf5. Por su parte, las células adiposas beige parecen descender de un linaje negativo a Myf5, ${ }^{52}$ si bien su origen exacto aún está en debate y se han planteado dos posibilidades: la primera sugiere que se derivan de precursores de adipocitos blancos y se convierten en adipocitos beige en respuesta a los estímulos del medio, como la exposición al frío; la segunda propone que los adipocitos blancos maduros pueden transdiferenciarse al tener contacto con los estímulos adecuados para convertirse en beige..$^{53}$ Finalmente, es factible que ambas propuestas sean correctas y que, dependiendo del medio ambiente, antecedentes genéticos y localización del tejido adiposo que contiene células beige, suceda una o la otra..$^{54}$

En condiciones basales, los adipocitos beige expresan una firma de marcadores moleculares parecida a la de los adipocitos blancos, pero después de su transdiferenciación adquieren un patrón de expresión similar a la de los adipocitos pardos. Es decir, un patrón de expresión termogénico que refleja mayor gasto de energía y consumo de oxígeno. ${ }^{55}$

El ejercicio es un estímulo que favorece la transdiferenciación del tejido adiposo blanco a tejido adiposo beige. En 2012 se supo que un péptido liberado por el músculo esquelético ejercitado de roedores podía influir sobre el "pardeamiento"' del tejido adiposo blanco. En el cultivo de adipocitos blancos de ratón, este péptido convertía a las células en positivas a UCP1, con un fenotipo beige; ese péptido fue nombrado irisina; ${ }^{56}$ se indicó que está presente en el suero y que su concentración aumenta después de entrenamiento de corto plazo. El incremento de irisina en la circulación tenía como consecuencia mayor expresión de genes mitocondriales y de consumo de oxígeno en el tejido adiposo blanco. A partir de entonces, la investigación sobre la irisina ha cobrado interés por la posible influencia de este péptido sobre el metabolismo del tejido adiposo blanco y, por lo tanto, sobre la obesidad. ${ }^{57}$

\section{Los matices de color del tejido adiposo, ¿cuál es la realidad clínica?}

Como se indicó, los adipocitos pardos y los beige comparten la habilidad de convertir la energía química en calor, contribuyendo a la termogénesis adaptativa. Sabemos que la presencia y activación de estos tipos celulares no están limitadas a la etapa neonatal, sino que pueden ser inducidas en humanos adultos.

En humanos adultos, las áreas de tejido adiposo pardo más comunes son la supraclavicular y la cervical. ${ }^{58}$ La región supraclavicular parece ser abundante en adipocitos pardos y beige y se ha establecido que su función metabólica correlaciona con el perfil metabólico global de los individuos. ${ }^{59}$

En estudios clínicos se ha demostrado que las mujeres tienen mayor masa de tejido adiposo pardo y beige en comparación con los hombres y que esta es más activa. También se ha establecido que a mayor adiposidad, menor contenido y actividad de tejido adiposo pardo y beige. De forma consistente, la pérdida de peso por cirugía bariátrica promueve un aumento en la masa y función del tejido adiposo pardo. ${ }^{60}$

En realidad, el tejido adiposo pardo en humanos está compuesto por una combinación de adipocitos pardos o beige multiloculares y de adipocitos blancos uniloculares. ${ }^{61}$ Existe evidencia de que estos depósitos de tejido adiposo están a la espera de señales del medio para "pardearse" y activarse, como se observó en los modelos animales. De esta forma, hormonas como la leptina, el factor de crecimiento fibroblástico 21 , los adrenérgicos y algunas citocinas promueven la termogénesis adaptativa, transdiferenciando los adipocitos blancos en las zonas de tejido adiposo pardo y aumentando su activación. Como consecuencia, la expresión de UCP1 y de otros marcadores de tejido adiposo pardo y beige se incrementa y el gasto energético es mayor, lo cual se acompaña de mejor tolerancia a la glucosa.

La termogénesis adaptativa generada por frío o por "tiritar" está claramente acompañada de cambios estructurales en el tejido adiposo pardo de los humanos, afectando la homeostasis energética. Por ejemplo, el cambio en la temperatura ambiental de 24 a 19 y $17^{\circ} \mathrm{C}$ aumenta la masa del tejido adiposo pardo, así como el gasto energético, por medio de mayor utilización de lípidos y glucosa. ${ }^{62}$ Debido a que la 
actividad física y "tiritar" inducen simultáneamente la producción calor y de irisina en el músculo, se ha estudiado la influencia de esta hormona sobre el "pardeamiento" o transdiferenciación del tejido adiposo blanco humano. Las investigaciones resultan controversiales. Las conclusiones de algunos estudios muestran que el entrenamiento físico en humanos adultos no aumenta significativamente la concentración de irisina, ni promueve la mayor expresión de genes relacionados con el "pardeamiento" del tejido adiposo, como UCP1, PGC-1b, PRDM16. ${ }^{57} \mathrm{Sin}$ embargo, otras investigaciones indican que durante la exposición al frío, la secreción de irisina es proporcional a la intensidad de la "tiritera" y similar a la inducida por el ejercicio de resistencia. El mismo grupo señala que la irisina induce la conversión de los preadipocitos humanos en adipocitos beige, generando a su vez más calor por termogénesis. ${ }^{62}$

Al parecer, en los humanos la irisina y otras señales son las responsables de provocar termogénesis adaptativa y cambio de los "matices de color" del tejido adiposo, sin embargo, lo anterior se tendrá que confirmar más adelante. Con todo, es claro que la plasticidad del tejido adiposo, su capacidad de interconversión, transdiferenciación y "pardeamiento" resultan en una oportunidad de modular el metabolismo energético. Finalmente, el conocimiento que se genere a partir de las vías que activan al tejido adiposo pardo o beige podría utilizarse para establecer intervenciones terapéuticas para contrarrestar la resistencia a la insulina y la obesidad.

\section{Conclusiones}

El estudio del tejido adiposo y sus funciones ha proporcionado valiosa información para el entendimiento y posible tratamiento de las alteraciones metabólicas que acompañan a la obesidad. El tejido adiposo blanco mantiene la homeostasis metabólica mediante la liberación regulada de adipocinas o lipocinas. A su vez, estas responden a las señales del medio promoviendo el hambre o la saciedad, la sensibilidad o resistencia a la acción de la insulina, la utilización o el almacenamiento de lípidos, la inflamación o coagulación, entre otros procesos. En el tejido adiposo blanco pueden generarse áreas con células pardas o beige que respondan a la actividad física o a necesidades de termogénesis, las cuales contribuyen al gasto de energía, tanto en modelos animales como en humanos. Para ello se requiere la remodelación del tejido adiposo, el cual resulta en un cambio en la vascularización, inflamación, hipoxia, patrón de expresión génica y contenido de factores proteicos y lipídicos. Finalmente, el conocimiento actual sobre los colores del tejido adiposo y sus matices da luz sobre la influencia del metabolismo global; en el futuro, podríamos disponer de herramientas para su modulación.

\section{Agradecimientos}

Al licenciado en Biología Experimental Daniel Dimitri Hernández Cueto y a la doctora Guillermina Baay Guzmán, por su apoyo para la obtención de la Figura 2 con la técnica de histología y tinción.

\section{Financiamiento}

El Instituto Danone otorgó el financiamiento número HIM/2016/079 SSA.1359, y la Secretaría de Educación Pública y el Consejo Nacional para las Ciencias y la Tecnología, el 28182 correspondiente a la convocatoria en Investigación Científica Básica.

\section{Bibliografía}

1. Thomas EL, Saeed N, Hajnal JV, Brynes A, Goldstone AP, Frost G, et al. Magnetic resonance imaging of total body fat. J Appl Physiol. 1998;85:1778-1785.

2. Després J. Is visceral obesity the cause of the metabolic syndrome? Ann Med. 2006;38:52-63.

3. Floch MH. Nettler's gastroenerology. EE. UU.: Elsevier; 2019.

4. Bays HE, González-Campoy JM, Bray GA, Kitabchi AE, Bergman DA, Schorr AB, et al. Pathogenic potential of adipose tissue and metabolic consequences of adipocyte hypertrophy and increased visceral adiposity. Expert Rev Cardiovasc Ther. 2008;6:343-368.

5. Tozzi M, Novak I. Purinergic receptors in adipose tissue as potential targets in metabolic disorders. Front Pharmacol. 2017;8:878.

6. LW. Histology cell and tissue biology. EE. UU.: Elsevier Biomedical; 1983.

7. Kershaw EE, Flier JS. Adipose tissue as an endocrine organ. J Clin Endocrinol Metab. 2004;89:2548-2556.

8. Szatkowski C, Vallet J, Dormishian M, Messaddeq N, Valet P, Boulberdaa $\mathrm{M}$, et al. Prokineticin receptor 1 as a novel suppressor of preadipocyte proliferation and differentiation to control obesity. PLOS One. 2013;8:e81175.

9. Rao RR, Long JZ, White JP, Svensson KJ, Lou J, Lokurkar I, et al. Meteorin-like is a hormone that regulates immune-adipose interactions to increase beige fat thermogenesis. Cell. 2014;157:1279-1291.

10. Hervey GR. The effects of lesions in the hypothalamus in parabiotic rats. J Physiol. 1959;145:336-352.

11. Parameswaran SV, Steffens AB, Hervey GR, de Ruiter L. Involvement of a humoral factor in regulation of body weight in parabiotic rats. Am J Physiol. 1977;232:R150-R157.

12. Coleman DL. Effects of parabiosis of obese with diabetes and normal mice. Diabetologia. 1973;9:294-298.

13. Campfield L, Smith FJ, Guisez Y, Devos R, Burn P. Recombinant mouse $O B$ protein: evidence for a peripheral signal linking adiposity and central neural networks. Science. 1995;269:546-549.

14. Neill US. A conversation with Jeffrey M. Friedman. J Clin Invest. 2013;123:529-530.

15. Unger $\mathrm{RH}$, Zhou $\mathrm{YT}$, Orci L. Regulation of fatty acid homeostasis in cells: novel role of leptin. Proc Natl Acad Sci U S A. 1999;96:2327-2332.

16. Unger RH. Lipid overload and overflow: metabolic trauma and the metabolic syndrome. Trends Endocrinol Metab. 2003;14:398-403.

17. Wilson-Fritch L, Nicoloro S, Chouinard M, Lazar MA, Chui PC, Leszyk J, et al. Mitochondrial remodeling in adipose tissue associated with obesity and treatment with rosiglitazone. J Clin Invest. 2004;114:1281-1289.

18. Nadler ST, Attie AD. Please pass the chips: genomic insights into obesity and diabetes. J Nutr. 2001;131:2078-2081. 
19. Kadowaki T, Yamauchi T, Kubota N, Hara K, Ueki K, Tobe K. Adiponectin and adiponectin receptors in insulin resistance, diabetes, and the metabolic syndrome. J Clin Invest. 2006;116:1784-1792.

20. Yatagai T, Nagasaka S, Taniguchi A, Fukushima M, Nakamura T, Kuroe $\mathrm{A}$, et al. Hypoadiponectinemia is associated with visceral fat accumulation and insulin resistance in Japanese men with type 2 diabetes mellitus. Metabolism. 2003;52:1274-1278.

21. Zhou Y, Zhang B, Hao C, Huang X, Li X, Huang Y, et al. Omentin: a novel adipokine in respiratory diseases. Int J Mol Sci. 2017;19:73.

22. Jaganathan R, Ravindran R, Dhanasekaran S. Emerging role of adipocytokines in type 2 diabetes as mediators of insulin resistance and cardiovascular disease. Can J Diabetes. 2018:42:446-456.

23. Yilmaz M, Claiborn KC, Hotamisligil GS. De novo lipogenesis products and endogenous lipokines. Diabetes. 2016;65:1800-1807.

24. Cao H, Gerhold K, Mayers JR, Wiest MM, Watkins SM, Hotamisligil GS Identification of a lipokine, a lipid hormone linking adipose tissue to systemic metabolism. Cell. 2008;134:933-944.

25. Yang $\mathrm{ZH}$, Miyahara $\mathrm{H}$, Hatanaka A. Chronic administration of palmitoleic acid reduces insulin resistance and hepatic lipid accumulation in KK-Ay Mice with genetic type 2 diabetes. Lipids Health Dis. 2011;10:120.

26. Chan KL, Pillon NJ, Sivaloganathan DM, Costford SR, Liu Z, Théret M, et al. Palmitoleate reverses high fat-induced proinflammatory macrophage polarization via AMP-activated Protein Kinase (AMPK). J Biol Chem. 2015;290:16979-16988

27. Talbot NA, Wheeler-Jones CP, Cleasby ME. Palmitoleic acid prevents palmitic acid-induced macrophage activation and consequent p38 MAPK-mediated skeletal muscle insulin resistance. Mol Cell Endocrinol. 2014;393:129-142.

28. Moraes-Vieira PM, Saghatelian A, Kahn BB. GLUT4 expression in adipocytes regulates de novo lipogenesis and levels of a novel class of lipids with antidiabetic and anti-inflammatory effects. Diabetes. 2016;65:1808-1815.

29. Hodson L, Fielding BA. Stearoyl-CoA desaturase: rogue or innocent bystander? Prog Lipid Res. 2013:52:15-42.

30. Hepler C, Gupta RK. The expanding problem of adipose depot remodeling and postnatal adipocyte progenitor recruitment. Mol Cell Endocrinol. 2017;445:95-108.

31. Cinti S. Transdifferentiation properties of adipocytes in the adipose organ. Am J Physiol Metab. 2009;297:E977-E986

32. Pérez-Miguelsanz MJ, Cabrera-Parra W, Varela-Moreiras G, Garaulet M Regional distribution of the body fat: use of image techniques as tools for nutritional diagnosis. Nutr Hosp. 2010;25:207-223.

33. Cornelius P. Regulation of adipocyte development. Annu Rev Nutr 1994:14:99-129.

34. Lafontan M. Adipose tissue and adipocyte dysregulation. Diabetes Metab. 2014; 40:16-28.

35. Seale P, Bjork B, Yang W, Kajimura S, Chin S, Kuang S, et al. PRDM16 controls a brown fat/skeletal muscle switch. Nature. 2008;454:961-967.

36. Saito M, Okamatsu-Ogura Y, Matsushita M, Watanabe K, Yoneshiro T, Iwanaga $T$, et al. high incidence of metabolically active brown adipose tissue in healthy adult humans: effects of cold exposure and adiposity. Diabetes. 2009;58:1526-1531.

37. van Marken-Lichtenbelt WD, Vanhommerig JW, Smulders NM, Drossaerts J, Kemerink GJ, Bouvy ND, et al. Cold-activated brown adipose tissue in healthy men. N Engl J Med. 2009;360:1500-1508.

38. Virtanen KA, Lidell ME, Orava J, Heglind M, Westergren R, Niemi T, et al. Functional brown adipose tissue in healthy adults. N Engl J Med. 2009:360:1518-1525.

39. Hibi M, Oishi S, Matsushita M, Yoneshiro T, Yamaguchi T, Usui C, et al. Brown adipose tissue is involved in diet-induced thermogenesis and whole-body fat utilization in healthy humans. Int $\mathrm{J}$ Obes (Lond). 2016;40:1655-1661.
40. Sánchez-Gurmaches J, Guertin DA. Adipocyte lineages: tracing back the origins of fat. Biochim Biophys Acta. 2014;1842:340-351.

41. Ricquier D, Bouillaud F. The uncoupling protein homologues: UCP1, UCP2, UCP3, StUCP and AtUCP. Biochem J. 2000;345:161.

42. Nakamura $Y$, Nakamura K. Central regulation of brown adipose tissue thermogenesis and energy homeostasis dependent on food availability. Pflügers Arch. 2018;470:823-837.

43. Seale P, Kajimura S, Spiegelman BM. Transcriptional control of brown adipocyte development and physiological function: of mice and men. Genes Dev. 2009;23:788-797.

44. Himms-Hagen J, Cui J, Danforth E, et al. Effect of CL-316,243, a thermogenic $\beta 3$-agonist, on energy balance and brown and white adipose tissues in rats. Am J Physiol. 1994

45. Collins S, Daniel KW, Petro AE, Surwit RS. Strain-specific response to beta 3-adrenergic receptor agonist treatment of diet-induced obesity in mice. Endocrinology. 1997;138:405-413.

46. Ghorbani M, Himms-Hagen J. Appearance of brown adipocytes in white adipose tissue during CL 316,243-induced reversal of obesity and diabetes in Zucker fa/fa rats. Int J Obes Relat Metab Disord. 1997;21:465-475.

47. Ghorbani M, Claus TH, Himms-Hagen J. Hypertrophy of brown adipocytes in brown and white adipose tissues and reversal of diet-induced obesity in rats treated with a $\beta 3$-adrenoceptor agonist. Biochem Pharmacol. 1997;54:121-131.

48. Cousin B, Cinti S, Morroni M, Raimbault S, Ricquier D, Pénicaud L, et al. Occurrence of brown adipocytes in rat white adipose tissue: molecular and morphological characterization. J Cell Sci. 1992;103:931-942.

49. Alcalá M, Calderón-Domínguez M, Serra D, Herrero L, Viana M. Mechanisms of impaired brown adipose tissue recruitment in obesity. Front Physiol. 2019;10:94

50. Harms M, Seale P. Brown and beige fat: development, function and therapeutic potential. Nat Med. 2013;19:1252-1263.

51. Kajimura S, Spiegelman BM, Seale P. Brown and beige fat: physiological roles beyond heat generation. Cell Metab. 2015;22:546-559.

52. Kiefer FW. Browning and thermogenic programing of adipose tissue. Best Pract Res Clin Endocrinol Metab. 2016;30:479-485.

53. Wang QA, Tao C, Gupta RK, Scherer PE. Tracking adipogenesis during white adipose tissue development, expansion and regeneration. Nat Med. 2013;19:1338-1344.

54. Kiefer FW. The significance of beige and brown fat in humans. Endocr Connect. 2017:6:R70-R79.

55. Ishibashi J, Seale P. Beige can be slimming. Science. 2010;328:1113-1114.

56. Boström P, Wu J, Jedrychowski MP, Korde A, Ye L, Long JZ, et al. A PGC1- $\alpha$-dependent myokine that drives brown-fat-like development of white fat and thermogenesis. Nature. 2012;481:463-468.

57. Irving BA, Still CD, Argyropoulos G. Does Irisin have a Brite future as a therapeutic agent in humans? Curr Obes Rep. 2014;3(2):235-241.

58. Nedergaard J, Bengtsson T, Cannon B. Unexpected evidence for active brown adipose tissue in adult humans. Am $\mathrm{J}$ Physiol Metab. 2007;293:E444-E452.

59. Wang W, Seale P. Control of brown and beige fat development. Nat Rev Mol Cell Biol. 2016;17:691-702.

60. Wu J, Cohen P, Spiegelman BM. Adaptive thermogenesis in adipocytes: is beige the new brown? Genes Dev. 2013;27:234-250.

61. Jespersen NZ, Larsen TJ, Peijs L, Daugaard S, Loft A, Mathur N, et al. A classical brown adipose tissue mRNA signature partly overlaps with brite in the supraclavicular region of adult humans. Cell Metab. 2013; $17: 798-805$

62. Celi FS. Human brown adipose tissue plasticity: hormonal and environmental manipulation. En: Research and perspectives in endocrine interactions. EE. UU.: Springer; 2017. 